\title{
Ambientes de Geometria Dinâmica: Potencialidades e Imprevistos
}

Guilherme Henrique Gomes da Silva

\begin{abstract}
Resumo
Apresenta-se nesse artigo resultados de uma pesquisa que verificou as contribuições pedagógicas de um ambiente de geometria dinâmica para futuros professores de matemática inseridos em um grupo de estudos. O grupo se reuniu para ler e discutir artigos científicos, explorar um software de geometria dinâmica e elaborar uma oficina para alunos do ensino médio de uma escola pública. 0 artigo destaca algumas atividades que foram elaboradas pelo grupo e situações ocorridas às quais inseriram os licenciandos em momentos imprevistos durante a oficina. Tais episódios são apresentados e é dada a atenção para necessidade do professor refletir sobre o imprevisto, visto que tal situação pode ser um potencial para aprendizagem tanto do professor quanto do estudante. Além disso, o artigo apresenta um contexto histórico do surgimento dos ambientes de geometria dinâmica e sua contextualização com a Educação Matemática.
\end{abstract}

Palavras-chave: geometria dinâmica; Geogebra; zona de risco; grupos de estudo.

\section{Abstract \\ Dynamic Geometry Environments: Potentials and Contingencies}

This paper presents results of a research aiming at analising how a study group, constituted by prospective mathematics teachers, used a dynamic geometry software in planning activities for a teaching practice. Before practicing with students, the group read and discussed papers, explored a dynamic geometry software, and planned a workshop to be held with students at high school level. The paper highlight the unpredictability which occurs in a ICT-based environment, and it is investigated how this unpredictability establishes a risk zone. These episodes are discussed and attention is given to the need of teachers reflecting on the unexpected, since this situation could be a potential for learning both the teacher and student. In addition, the article presents a historical context 
of the emergence of dynamic geometry environments and its context in mathematics education.

Keywords: dynamic geometry; Geogebra; risk zone; study group.

\section{Introdução}

Atualmente diversas pesquisas evidenciam o potencial da utilização das novas Tecnologias da Informação e Comunicação (TIC) no ensino e aprendizagem da matemática. Isso decorre da grande influência que elas causam na sociedade e no modo de vida das pessoas do mundo contemporâneo. Diariamente softwares são desenvolvidos nas mais diferentes áreas, como lazer, trabalho e educação. Nesta última, muitos projetos foram desenvolvidos ligados a temas da Matemática como álgebra, cálculo, linguagem de programação, lógica matemática, geometria plana e geometria espacial.

Este artigo destaca em especial uma modalidade de programas que trabalha com objetos geométricos de uma forma interativa, que propiciam a criação de um ambiente de aprendizagem diferenciado para o ensino e aprendizagem da geometria, apresentando uma nova maneira de visualização tanto dos objetos da geometria euclidiana quanto de outras geometrias, como a hiperbólica, analítica ou projetiva. Nesse ambiente os objetos não permanecem de forma estática, sem movimento. O usuário é capaz de interagir com as construções geométricas, realizando movimentos como translações, rotações, modificação de tamanho, além de outras possibilidades. São os softwares baseados na geometria dinâmica.

Um ambiente de geometria dinâmica pode ser definido como um software cuja característica principal é a possibilidade de "arrastar" as construções geométricas com o mouse, ao mesmo tempo em que suas medidas são atualizadas. Goldenberg, Scher e Feurzeig (2008), afirmam que tais ambientes permitem aos estudantes criarem construções geométricas e manipulá-las facilmente, movendo livremente elementos de um desenho e observando outros que correspondem às condições alteradas. Dessa maneira a tela do computador fornece a impressão de que a construção geométrica está sendo deformado continuamente em todo o processo de arrastar, enquanto mantém as relações que foram especificadas como essenciais da construção original.

No decorrer do texto serão focadas as potencialidades pedagógicas desses ambientes de aprendizagem e apresentadas algumas situações em que possíveis imprevistos podem surgir quando professores os utilizam em suas aulas. Para tanto serão apresentados alguns resultados de uma pesquisa que analisou a maneira que participantes de um grupo de estudos, formado exclusivamente por futuros professores de matemática, se aproprioudo software Geogebrae analisar as contribuições que a participação nesse grupo propiciou a seus integrantes. Nesse 
artigo serão apresentadas reflexões dos futuros professores no que diz respeito à elaboração das atividades no ambiente de geometria dinâmica e serão evidenciados imprevistos que surgiram ao se trabalhar nesse ambiente.

Os dados da pesquisa são oriundos de gravações em áudio-visual dos encontros realizados pelo grupo e das anotações do caderno de campo do pesquisador e dos participantes. Participaram das reuniões, além do pesquisador, seis licenciandos. Foram realizados oito encontros para estudo, elaboração das atividades de geometria dinâmica e aplicação em uma escola pública. Nesta última foram utilizados dois encontros e participaram estudantes do primeiro ano do ensino médio. Para a análise dos dados foi utilizada uma abordagem qualitativa, já que se buscou a compreensão de elementos de uma situação que envolveu o cotidiano do futuro professor de matemática, além de sentimentos, crenças, motivações e atitudes individuais. Tal opção vem ao encontro de Bicudo (2006), onde a autora afirma que o qualitativo "engloba a ideia do subjetivo, passível de expor sensações e opiniões" (p.106). Além disso, "o significado atribuído a essa concepção de pesquisa também engloba noções a respeito de percepções de diferenças e semelhanças de aspectos comparáveis de experiências" (p.106).

Nas reuniões do grupo os futuros professores estudavam previamente livros e artigos científicos sobre assuntos como geometria plana, utilização das Novas Tecnologias da Informação e Comunicação na Educação Matemática e teóricos que abordavam o tema Investigação Matemática em sala de aula. Os licenciandos discutiam assuntos previamente combinados e todos apresentavam seu ponto de vista além de tirarem dúvidas sobre os estudos, argumentarem sobre experiências anteriores e apresentarem ideias para as atividades que posteriormente seriam aplicadas. Depois desse momento de discussão o grupo se separava em duplas ou individualmente e trabalhava na elaboração de atividades que seguiam a perspectiva investigativa estudada por eles. No término de cada encontro eles se reuniam e apresentavam o que cada um tinha feito, para que os colegas colaborassem com ideias ou ajudassem em dúvidas conceituais.

Para a elaboração das atividades o grupo utilizou uma abordagem investigativa, baseado nas pesquisas de Ponte, Brocardo e Oliveira (2006) e Skovsmose (2008). Nessa perspectiva, os alunos são convidados a procurar regularidades, explorar a atividade, elaborar conjecturas, realizar testes, discutir com os colegas os resultados encontrados, principalmente, refletir sobre assuntos da matemática.

Vale destacar que antes da realização dos encontros todos os integrantes do grupo de estudos participaram de um curso de extensão na qual aprenderam a manusear as ferramentas do software Geogebra. Graças a isso, os futuros professores tiveram autonomia para construir e elaborar as atividades na plataforma do programa.Tais atividades foram aplicadas em uma escola pública com estudantes do primeiro ano do ensino médio em dois encontros, onde, em cada um 
deles, dois participantes do grupo foram os professores responsáveis da turma e o restante ficava ao fundo do laboratório de informática anotando suas observações em seus cadernos de campo.

A seguir, serão apresentadas algumas considerações importantes sobre o contexto histórico dos ambientes de geometria dinâmica e, em seguida, episódios oriundos dos encontros do grupo de estudos.

\section{Contexto histórico dos ambientes de geometria dinâmica}

O surgimento dos ambientes de geometria dinâmica está relacionado com a evolução da informática na sociedade. No final da década de setenta, o aparecimento dos ícones na tela dos computadores foi um grande marco para a história da computação, contribuindo para a disseminação dos computadores na sociedade daquela época. A possibilidade de manipular objetos diretamente na tela do computador com o uso do mouse revolucionou a forma de se trabalhar com a máquina, já que não era mais necessário utilizar comandos simbólicos diretamente do teclado para realizar algum procedimento, o que possibilitou a abertura para novas técnicas de trabalho em diferentes áreas.

Esse fato foi um incentivo para que um grupo de pesquisadores franceses desenvolvesse uma ferramenta computacional para permitir a exploração da Teoria dos Grafos. A Teoria dos Grafos é um ramo da matemática que estuda as relações entre os objetos de um determinado conjunto. Grafo é um par $(\mathrm{V}, \mathrm{A})$ onde $\mathrm{V}$ é um conjunto arbitrário de objetos denominados vértices e $A$ é um conjunto de pares não ordenados de $V$, chamado arestas. É possível associar a teoria dos grafos a, por exemplo, circuitos elétricos, estruturas de moléculas de hidrocarboneto, conectividade da internet, modelos na biologia, informática, estruturação de um software, entre outros.

O projeto visava ajudar os pesquisadores em seus trabalhos colocando a tecnologia como uma ferramenta para explorar e conjecturar. A facilidade fornecida pelo computador para olhar $o$ mesmo grafo em diferentes combinações, "arrastando" seus vértices com o uso do mouse pela tela foi a mais importante motivação para o início do projeto batizado de Cahier de Brouillon Informatique for Graph Theory (Cabri-graph). A Figura 1 mostra a maneira que o grafo bipartido completo de quatro vértices, $\mathrm{K} 4,4$, menos um emparelhamento perfeito (os vértices verticais), pode ser transformado em um grafo do cubo tridimensional no ambiente computacional. Utilizando outro ambiente esse processo poderia não ser notado. 

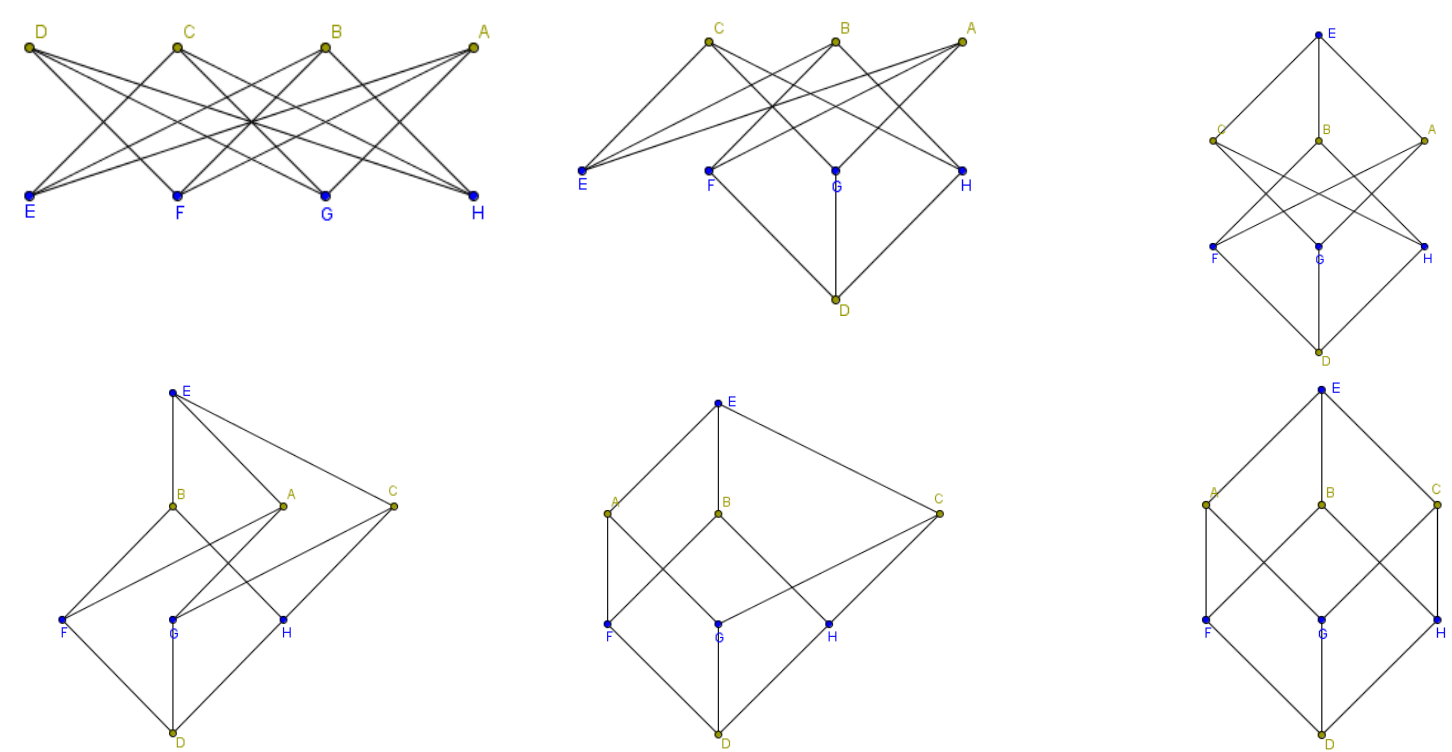

Figura 1 - Do grafo K4,4 - EP ao cubo ordinário Q3 em cinco arrastos in

Laborde e Laborde (2008, p.33)

Algum tempo depois da criação do projeto, Jean-Marie Laborde, um dos desenvolvedores do Cabri-graph, percebeu uma característica comum entre a geometria e a teoria dos grafos: a importância da visualização. Dessa forma o pesquisador propôs utilizar a capacidade do arrastar do Cabri-graph para a geometria euclidiana, facilitando assim a construção e manipulação de objetos geométricos, já que estes passaram a ganhar movimentos, podendo ser arrastados pela tela do computador sem perder as propriedades que os definiam. De acordo com Laborde e Laborde (2008) as especificações desse projeto foram dadasa dois grupos: estudantes do último ano de engenharia da computação e matemática aplicada da Grande Ecole de Ingénieurs ENSIMAG para desenvolvê-lo como um projeto; e para a Companhia Apple Computer. Iniciava então o surgimento do software Cabri-Géomètre, que mais tarde se disseminaria para todos os níveis da educação tanto na França quanto em vários países do mundo, se tornando um dos mais importantes e mais conhecidos softwares de geometria dinâmica existentes, marcando assim o inicio da geometria dinâmica.

O surgimento e a evolução do Cabri-Géomètre, e consequentemente da geometria dinâmica, sãodiscutidos emLaborde e Laborde (2008). De acordo com os autores, em 1985 a Apple forneceu computadores LISA ${ }^{1}$ para a realização do projetode criação do software. Nesse

${ }^{1}$ Primeiro computador pessoal lançado pela Apple Computer a ter um mouse e uma interface gráfica. 
mesmo ano sua codificação começou a ser desenvolvida para computadores Macintosh e LISA usando Lightspeed C, um ambiente integrado de programação que foi o primeiro a ter implementado o conceito de ligação dinâmica. Em 1986, sobre a liderança de Jean-Marie Laborde, surge o primeiro protótipo do Cabri-Géomètre, desenvolvido pelos pesquisadores Franck Bellemain, Philippe Cayet e Yves Baulac. Esse protótipo foi testado por um mês pelo professor de matemática Bernard Capponi, que lecionava em uma escola aos redores de Grenoble, na França. Em 1987 uma prévia tecnológica do Cabri ocorreu na conferência do International Group for the Psychology of Mathematics Education (PME 11) em Montreal. Já em 1988 foi produzido um protótipo funcional do Cabri, que foi amplamente utilizado por vários professores, em especial na Suíça, onde as escolas participantes foram equipadas com computadores do tipo Macintosh. A primeira apresentação pública do Cabri ocorreu em 1988 no International Congress on Mathematical Education (ICME 6) em Budapeste. Em 1989 o Cabri foi publicado na França e em 1990 foi oficialmente reconhecido como um projeto da IMAG, laboratório associado da Grenoble CNRS $^{1}$. Em meados de 1995 uma prévia dessa tecnologia foi lançada pela Texas Instrumentsa qual até hoje é responsável pela comercialização do Cabri-Géomètre. Em 1994 foi lançada a segunda geração do Cabri para Macintosh e apenas em 1998 foi lançada sua versão para Windows.

A disseminação dos softwares baseados em ambientes de geometria dinâmica ocorreu no final dos anos 80. Apesar do Cabri-Géomètre ter sido um dos pioneiros nessa abordagem, outros programas foram surgindo paralelamente a ele. Um dos mais importantes foi oGeometer's Sketchpad. Apesar de ambos, Cabri e Sketchpad, terem sido desenvolvidos na mesma época e possuírem um design semelhante, Goldenberg, Scher e Feurzeig (2008) destacam que nenhum de seus desenvolvedores conhecia o trabalho do outro.

O Sketchpad começou a ser desenvolvido na metade da década de oitenta, dirigido por Eugene Klotz e Doris Schattschneider. O software surgiu de um projeto chamado Visual Geometry Project que tinha por objetivo desenvolver uma série de vídeos que focaria a geometria tridimensional e seriam gravados utilizando um programa computacional. Para tanto, Klotz contatou um jovem programador chamado Nicolas Jackiw. No decorrer do projeto a dificuldade de programar em um ambiente 3D foi o grande empecilho para sua realização. Dessa forma Klotz e Schattschneider decidiram utilizar um ambiente bi-dimensional para o programa, surgindo então a primeira versão do Geometer's Sketchpad.

Goldenberg, Scher e Feurzeig (2008) entrevistaram os desenvolvedores do Cabri-Géomètre e do Geometer's Sketchpad. Nesse trabalho, os autores puderam perceber que ambos tinham cinco princípios que guiaram seus pensamentos na criação dos softwares: $O$ arrastar, que de fato tornou-se a principal característica desses softwares; a pequena distância em relação à geometria euclidiana, já que a todo o momento os desenvolvedores dos programas tentavam

${ }^{1}$ Equivalente ao CNPq brasileiro.

R. B. E. C. T., vol 5, núm 1, jan./abr. $2012 \quad$ ISSN - 1982-873X 
encontrar um modelo para seu sistema que fosse o mais próximo do comportamento da geometria plana; a reversibilidade dos objetos geométricos, que seria quando, por exemplo, ao arrastar um objeto para alguma posição da tela o usuário poderia retornar à posição anterior encontrando um objeto idêntico àquele que fora arrastado de início; a continuidade, tão difícil de ser implantada no modelo matemático dos programas e a minimização de momentos de estranhamento pelo usuário do programa.

Uma possível situação que exemplifica essa minimização seria, por exemplo, quando um usuário desejasse marcar um ponto B sobre um segmento de reta. De acordo com a definição da geometria euclidiana, esse ponto deve permanecer sobre o segmento mesmo quando ele for rotacionado ou transladado. Não seria nenhuma inconsistência matemática se o usuário escolhesse que esse ponto estivesse a uma distância fixa do ponto do extremo do segmento (fixo ou não). Porém uma inconsistência poderia surgir quando os pontos dos extremos do segmento fossem arrastados separadamente. Ao arrastá-los suficientemente próximo um do outro, o ponto B poderia parecer "saltar para fora" do segmento, surgindo assim algo estranho em termos visuais para o usuário do programa. Os desenvolvedores dos softwares tentavam limitar ao máximo esses tipos de conflitos.

O final da década de oitenta foi um marco histórico importante para a geometria dinâmica já que, nesse período, os softwares baseados nessa perspectiva foram diferenciados dos demais que trabalhavam com geometria plana. Isso ocorreu na Conferência Internacional sobre inteligência artificial e educação Intelligence Learning Environments: The Case of Geometry. A conferência foi organizada pela equipe do Cabri-Géomètre e é considerado um acontecimento muito importante para a geometria dinâmica.

Mesmo aparentando muitas vantagens, tanto matemáticos, educadores matemáticos e cientistas da computação possuíam receio em trabalhar nesses ambientes. Laborde e Laborde (2008) destacam que externalizar objetos matemáticos abstratos e suas inter-relações poderia ser considerado como a reduçãodo trabalho criativo de um matemático para um de observação da realidade. Os educadores matemáticos, talvez influenciados pelo não uso dos softwares pelos matemáticos, não desenvolveram, nos primeiros anos do surgimento dos ambientes de geometria dinâmica, abordagens teóricas sobre o uso dessas ferramentas e também não os utilizavam em seu cotidiano escolar. A maioria dos cientistas da computação simplesmente desprezava a capacidade do arrastar dos softwares e os usavam apenas como um editor de diagramas.

Por volta dos anos de 1992 e 1993 essa fase de "estranhamento" pela comunidade de Educação Matemática e de Matemáticos começava a desaparecer. Nessa época, muitos estudos começavam a ser realizados baseados nos ambientes de geometria dinâmica, tanto na pesquisa educacional quanto na pesquisa matemática. Nas pesquisas matemáticas, por exemplo, usando o 
Cabri, Dickey (1995, apud Laborde e Laborde 2008) descobriu novas configurações de cônicas introduzidas por Steiner conectado com o famoso teorema de Pascal. Nas pesquisas em Educação Matemática, por exemplo, problemas teóricos que relatavam a interação entre diagramas e objetos geométricos começavam a emergir.

Tanto o Cabri-Géomètre quanto o Geometer's Sketchpad foram muito importantes para o surgimento e disseminação da geometria dinâmica pelo mundo. A partir da metade da década de 90 eles se espalharam rapidamente por todos os continentes. Vários países começaram a equipar suas escolas com computadores e com softwaresdessa categoria. Isso contribuiu para que outros programas de geometria dinâmica começassem a surgir. Um desses foi o Geogebra, criado em 2001 pelo pesquisador Markus Hohenwarter na Universität Salzburg ${ }^{1}$. Diferente do Cabri e do Sketchpad, o Geogebra possui licença livre. É escrito em linguagem JAVA² e isso permite estar disponível em várias plataformas.

A característica principal do Geogebra, o qual trouxe grande inovação na geometria dinâmica,é a combinação de geometria, álgebra e cálculo em um único ambiente. A visualização de um objeto possui um correspondente geométrico e um algébrico. Por exemplo, uma circunferência pode ser modificada arrastando um de seus pontos pela tela do computador ou então modificando sua equação algébrica.

Na sua versão mais atual (4.0) também é possivel trabalhar simultaneamente com tabelas, gráficos e estatística. Isso permite o trabalho com planilhas dinâmicas e utilizar ferramentas para análise de dados. Também nessa versão foi incluída uma calculadora de probabilidades e a possibilidade de trabalhar com equações e inequações implícitas.

A Figura 2 mostra a área de trabalho do Geogebra. Do lado esquerdo está localizada a janela algébrica, onde todo correspondente da janela de visualização possui um correspondente. Abaixo há o campo de entrada, onde é possível, através de comandos, realizarem diversas tarefas.

Figura 2 - Área de trabalho do Geogebra

\footnotetext{
${ }^{1}$ http://www.uni-salzburg.at

${ }^{2}$ www.java.com
}

R. B. E. C. T., vol 5, núm 1, jan./abr. 2012

ISSN - 1982-873X 


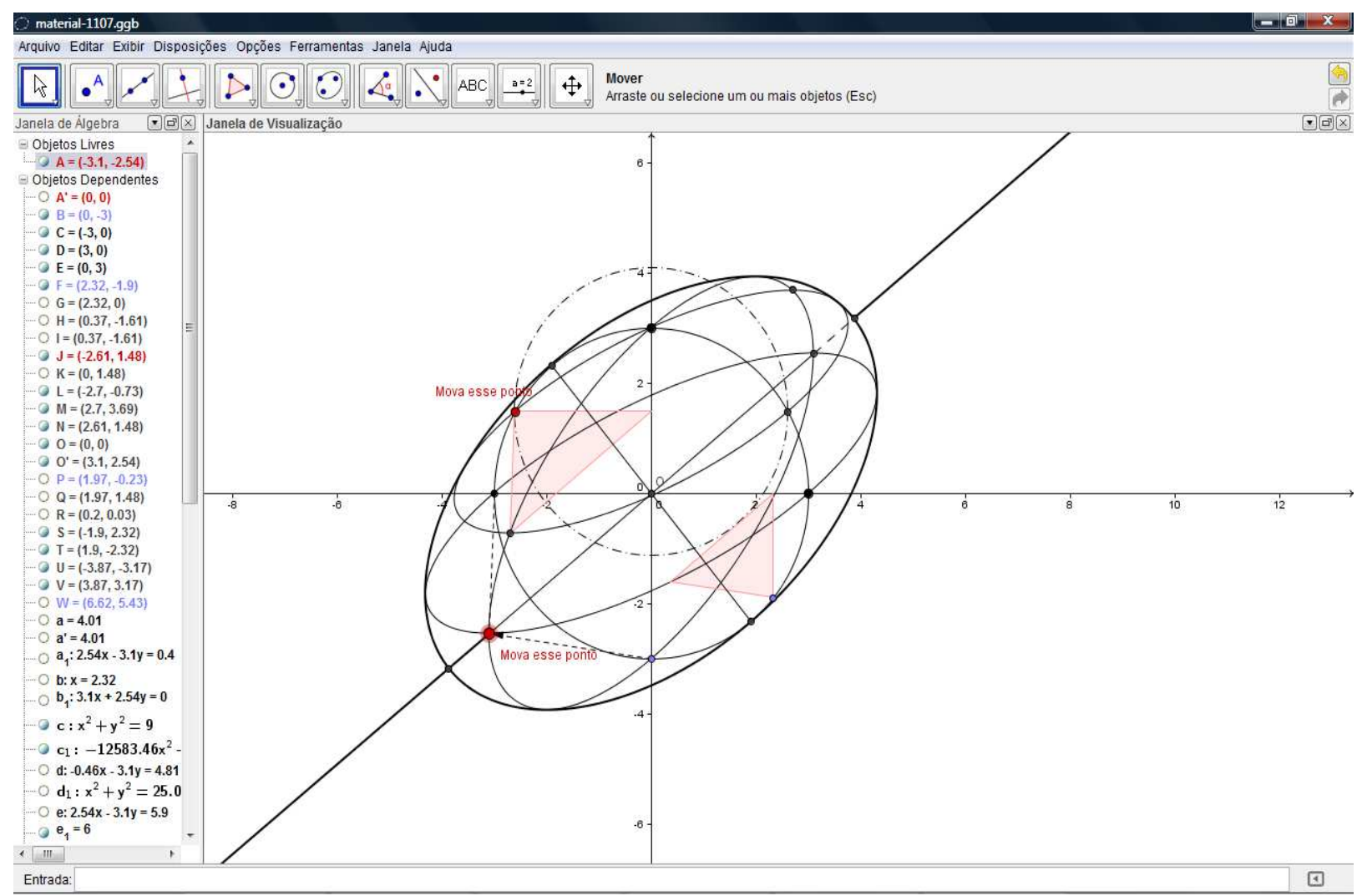

Figura 2 -Área de trabalho do Geogebra 
Na Figura 3 pode-se observar a possibilidade de alternar a janela algébrica para uma planilha dinâmica.

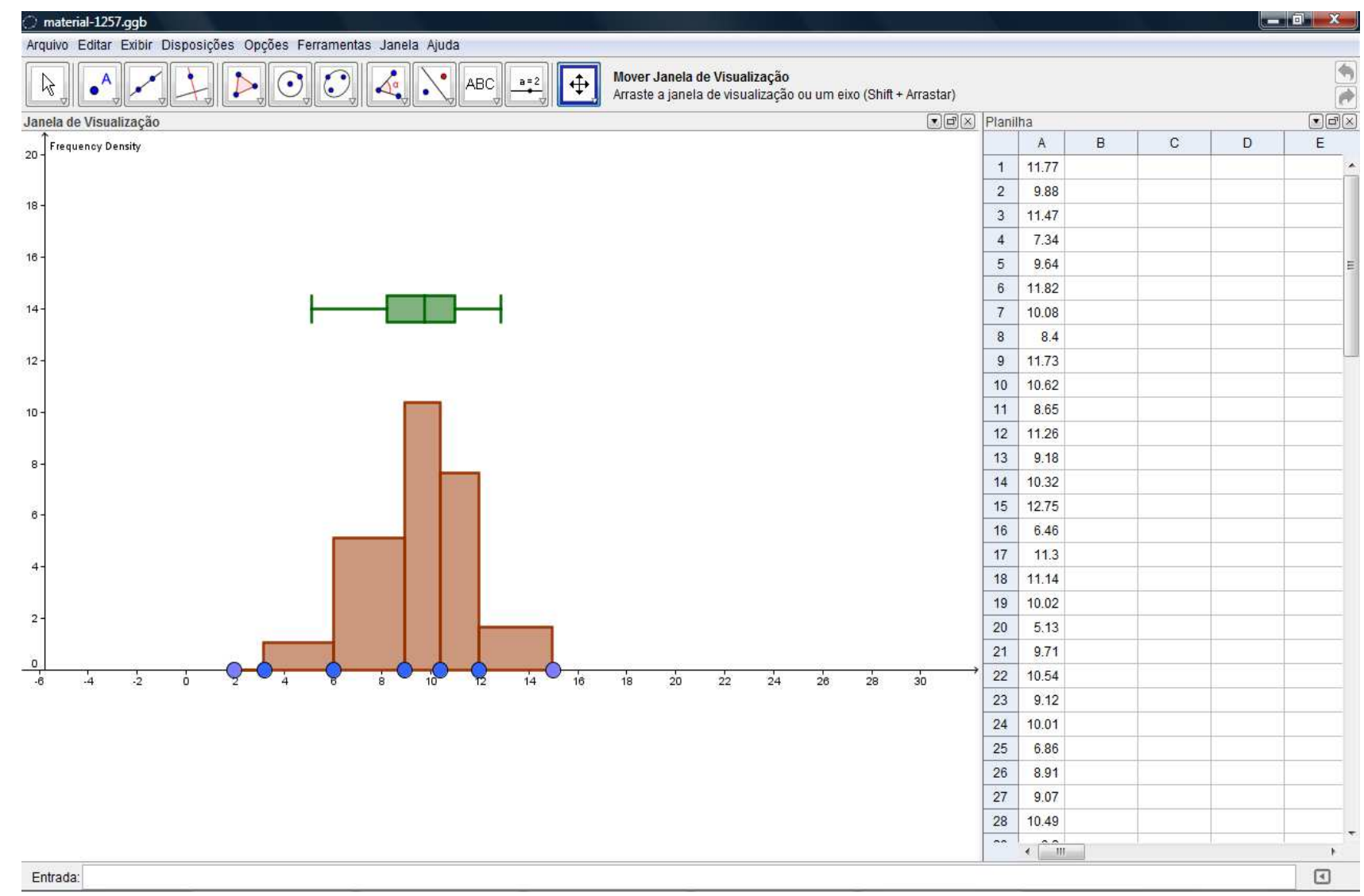

Figura 3 - Área de trabalho do Geogebra - utilizando planilhas dinâmicas na construção de um histograma

A geometria dinâmica mudou e vem mudando a maneira de se conceber o ensino e aprendizagem da matemática. Diariamente novos programas são criados e novas ferramentas são incluídas em softwares já existentes. Como foi possível verificar até agora, o Cabri-Géomètre e o Geometer's Sketchpad foram os primeiros a criarem a concepção de "dinamismo" existente nesses ambientes, abrindo as portas para que pesquisas fossem feitas e novos softwares fossem criados.

\section{O Trabalho em um ambiente de Geometria Dinâmica}

Nesta seção, serão apresentadas algumas atividades de geometria dinâmica bem como as situações que ocorreram quando o grupo de estudos aqui apresentado aplicaram-nas em uma oficina pedagógica realizada em uma escola pública para alunos do primeiro ano do ensino médio.Essa oficina foi realizada em dois encontros e contou com o empenho de seis alunos do curso de Licenciatura em Matemática de uma universidade do interior de São Paulo. 
Para a elaboração da oficina os participantesdo grupo realizaram oito reuniões e estudaram teóricos da Educação Matemática estabelecendo assim um embasamento para desenvolverem as atividades voltadas para o ensino de geometria plana. Os futuros professores estudaram o livro "Informática e Educação Matemática" de Borba e Penteado (2002), que forneceu todo o apoio na utilização das Novas Tecnologias da Informação e Comunicação (TIC) em sala de aula, apresentando vários exemplos de atividades e situações que o professor pode se deparar quando está inserido nesse ambiente.

O grupo também se baseou em dois livros que guiaram sua concepção na elaboração das atividades. Trata-se de "Desafios da Reflexão em Educação Matemática Crítica" de Skovsmose (2008) e "Investigação Matemática em sala de aula" de Ponte, Brocardo e Oliveira (2006). Tais teóricos fundamentaram a perspectiva de atividades investigativas utilizada pelo grupo ao elaborar as atividades. De acordo com Skovsmose (2008), nessa perspectiva estudantes são inseridos em um cenário de investigação, o qual requer do professor e de seus alunos um senso investigativo, já que devem procurar conhecer o que não sabem, trabalhando como matemáticos profissionais. Isso não significa que estarão construindo novos conhecimentos ou teoremas, mas terão a possibilidade de explorar e formular suas próprias conjecturas, lançar seus próprios contra-exemplos, apresentar os resultados de sua investigação aos colegas e argumentar sobre fatos matemáticos que, na maioria das vezes, são vistos como irrefutáveis ou inquestionáveis. Isso faz com que os alunos aprendam Matemática fazendo Matemática.

Para elaborar a oficina pedagógica, os participantes do grupo optaram por utilizar o software Geogebra, devido à licença livre que ele possui e por possibilitar a dupla percepção dos objetos (algébrica e geométrica).Nas atividades houve a preocupação em conduzir os alunos a formular questões e procurar explicações, como proposto por Skovsmose (2008). Em todas as atividades havia um espaço destinado para as anotações, pois os participantes do grupo acreditavam que nelas seria possível verificar, mesmo depois da aula, os caminhos e estratégias utilizados pelos alunos bem como suas conclusões. Ponte, Brocardo e Oliveira (2006) afirmam que essa síntese da atividade é um momento muito importante, pois permite que os alunos reflitam sobre o processo investigativo, aprendendo com e sobre ele. Na preparação da oficina, o grupo criou e adaptou diversas atividades. Nas adaptadas os futuros professores se basearam em vários livros do ensino médio que foram disponibilizados nos encontros. A seguir, serão destacadas algumas dessas atividades e alguns imprevistos que surgiram em sua aplicação.

Destaca-se na Tabela 1 uma atividade que faz referência ao que Skovsmose (2008) define como semi-realidade. De acordo com esse autor,esse enfoque traz aspectos do mundo real ao alcance do estudante. Nessa atividade são destacados os conceitos de perímetro e área de um 
quadrilátero. $\mathrm{O}$ objetivo buscado pelo grupo foi que o aluno percebesse, através de um campo de beisebol, que a área do quadrilátero é máxima quando este é um quadrado.

Tabela 1 - Atividade sobre o campo de beisebol

Para realizar essa atividade você precisa saber o conceito de Perímetro e de área de um quadrilátero. Anote o que você sabe sobre esses temas.

Um rebatedor de beisebol localizado sobre o ponto $A$, tem de percorrer o perímetro do quadrilátero para conseguir um home run, e marcar um ponto.

1 - Arrastando o ponto $D$ sobre o setor circular, o que acontece com o perímetro do quadrilátero? Quanto é possível ter o maior perímetro do campo?

2 - O que acontece com a área do quadrilátero quando você arrasta o ponto D? Quando é possível obter a maior área? Justifique seu raciocínio.

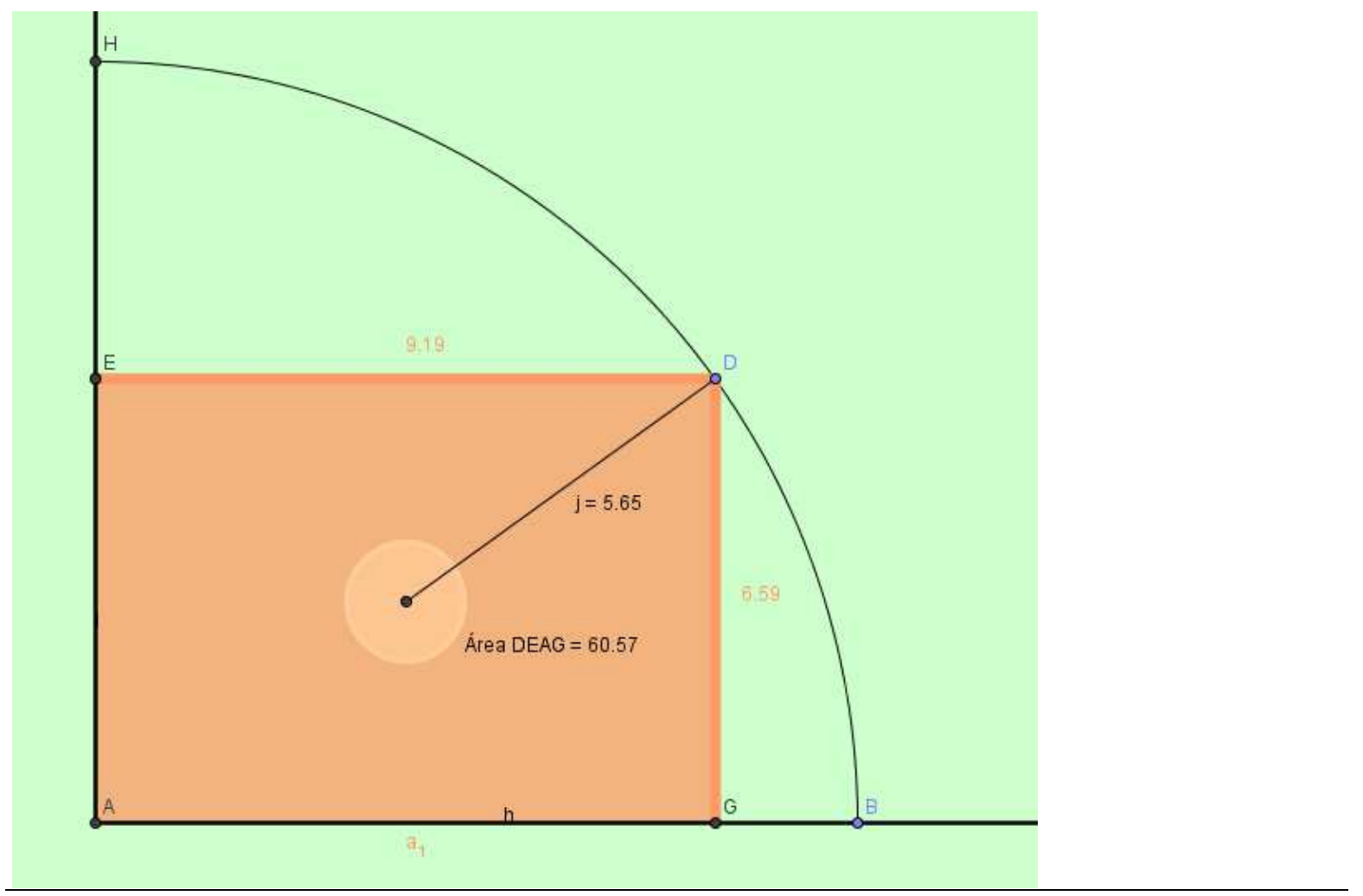

Utilizando a teoria discutida durante os encontros o grupo foi capaz de preparar as atividades da oficina evidenciando o caráter investigativo das mesmas. Todas apresentaram tal preocupação e buscava direcionar os estudantes com perguntas do tipo "o que acontece se..." despertando questionamentos do tipo "sim, o que acontece se...". Para Skovsmose (2008) essa é uma das características de um ambiente de aprendizagem baseado na investigação matemática.

A Tabela 2 mostra outra atividade elaborada pelo grupo em que também é possível notar a preocupação dos futuros professores em inserir os estudantes em um cenário de investigação.

Tabela 2 - atividade sobre área do triângulo

Para essa atividade você precisa saber o conceito de área de um triângulo. Anote o que 
você sabe sobre isso. Se necessário, peça auxílio para seu professor.

1. O que acontece com a área do triângulo se arrastarmos os pontos $D$ e $E$ ?

2. O que acontece se arrastarmos o ponto F? Como ficou a área do triângulo? Por que isso ocorre?

3. Agora, o que acontece se arrastarmos o ponto C? Por que isso ocorre?

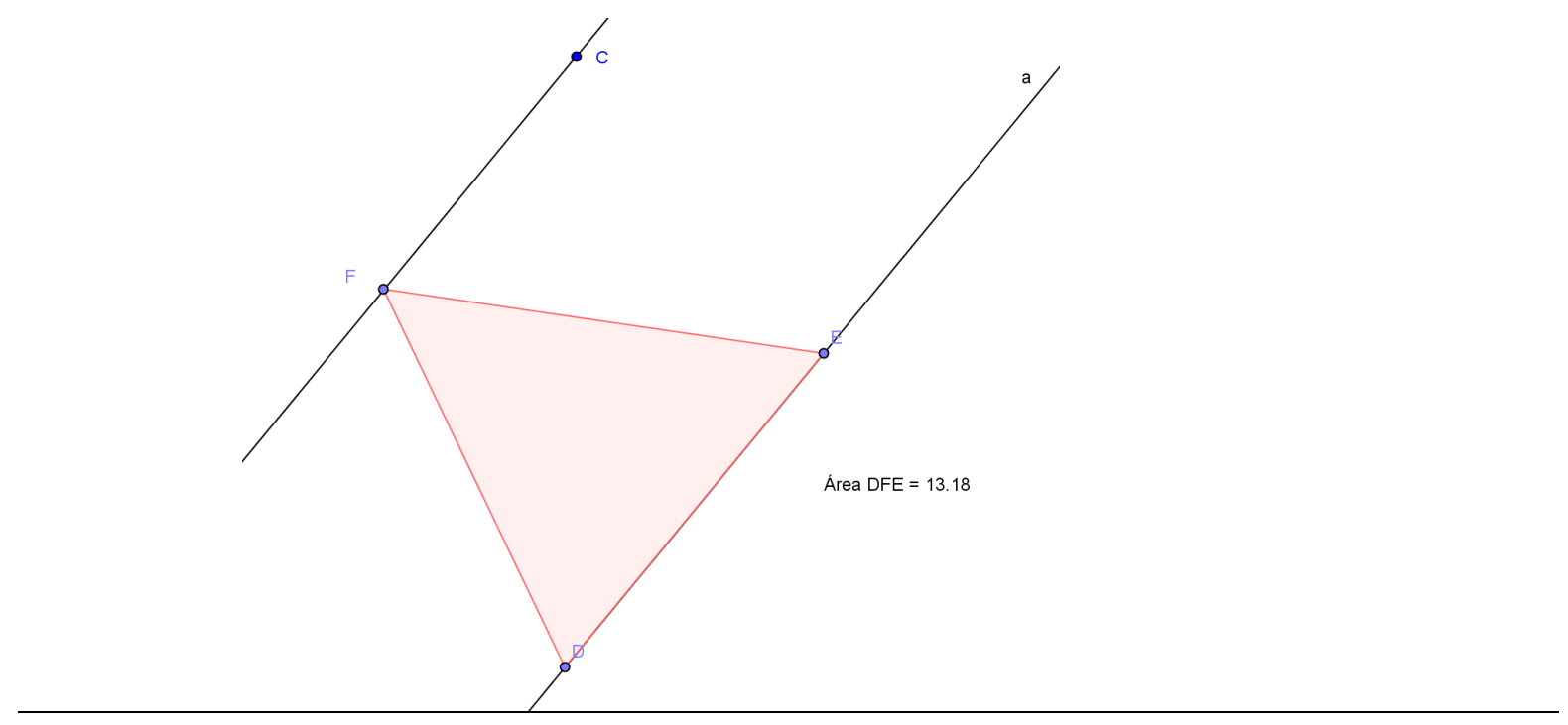

Esta atividade convidava os estudantes a investigarem a área de um triângulo, observando que ela só se alterava quando a base era modificada. Quando o ponto $F$ era arrastado sobre a reta,a altura não se modificava e, consequentemente, não alterando a área do triângulo.

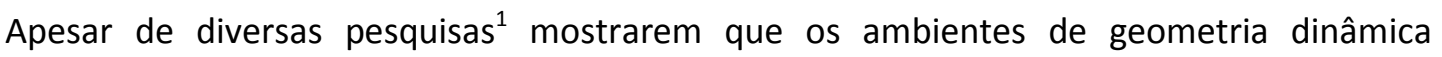
possuem grande potencial pedagógico para o ensino e aprendizagem da matemática, é comum que professores optem por não os utilizarem em seu cotidiano. Isso acontece já que os ambientes baseados em tecnologia informática apresentam maior potencial para o surgimento de situações imprevistas, implicando na necessidade de que o professor assuma riscos durante a aula.

De acordo com Penteado (2001), uma razão para isso é que engajar-se em trabalhos que fazem uso de recursos pedagógicos que utilizam a tecnologia informática é algo como sair de uma zona caracterizada pelo conforto proporcionado pelo controle da situação e atuar em uma zona de risco, onde o imprevisto predomina. Para a autora, os ambientes baseados em TIC propiciam tais imprevistos com mais frequência, pois o professor pode se deparar com situações inesperadas como o mau funcionamento de um computador ou um apertar de teclas pelos estudantes que leve a uma situação não esperada. Nesse cenário o professor está mais propicio a

\footnotetext{
${ }^{1}$ Borba e Penteado (2002), Valente (1993), Valente (2003), Richit (2005), Olive (1998), Golderberg
} e Cuocco (1998). 
sair de uma zona de conforto, caracterizada pela previsibilidade do ambiente, e entrar em uma zona de risco, que requer tomada de decisão sobre situações nunca antes experenciadas. De acordo com Penteado e Skovsmose (2008) uma zona de risco, apesar de parecer um momento negativo, é na verdade um espaço que precisa ser explorado pelo professor para ampliar as possibilidades de aprendizagem dos alunos.

Essa situação foi sentida na prática pelos futuros professores. Algumas atividades elaboradas por eles acabaram inserindo-os diante dessa zona de risco. Mesmo com estudos e testes prévios, não foi possível prever que as atividades os levariam a uma situação inusitada.

O grupo de estudos elaborou uma atividade que convidava os estudantes a investigarem a propriedade de que, em um paralelogramo, mesmo arrastando e modificando as posições de seus vértices, os ângulos opostos sempre são iguais. Conforme mostra a Figura 4, a ideia da atividade era que os pontos $A, B, C$ e $D$ do paralelogramo fossem arrastados pela tela do computador e o aluno verificasse que realmente os ângulos opostos continuavam iguais.

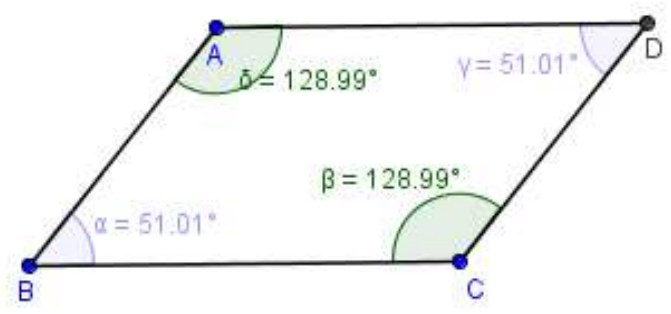

Figura 4-Atividade elaborada pelo grupo

Nessa atividade, aparentemente, nada poderia sair errado. Apesar disso, quando um estudante arrastou o ponto A "para trás" do ponto B, invertendo a posição do paralelogramo, o software acabou mudando a marcação dos ângulos de interno para externo, conforme pode ser notado na Figura 5.

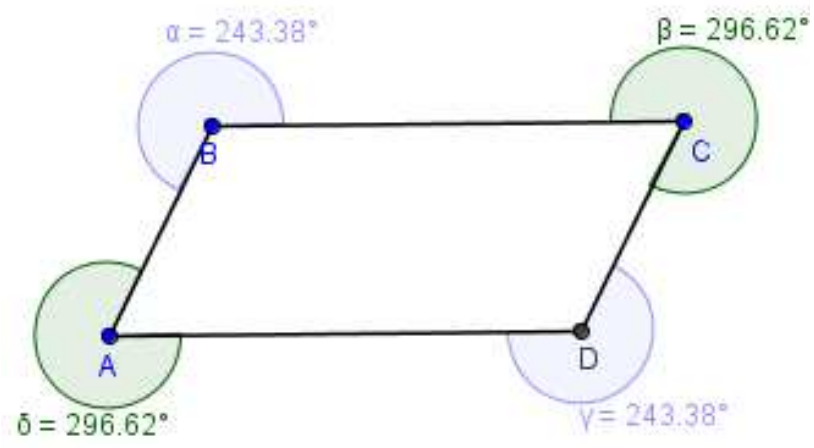

Figura 5 - Atividade elaborada pelo grupo

R. B. E. C. T., vol 5, núm 1, jan./abr. 2012 ISSN - 1982-873X 
A participante do grupo de estudos que estava conduzindo a atividade com a turma, ao se deparar com essa situação, tentou recuar perante a zona de risco, voltando para uma zona de conforto, ao dizer para o aluno que o foco da aula era analisar os ângulos internos do paralelogramo e não os externos, limitando assim outras possibilidades de aprendizagem que estavam aparecendo na atividade. Essa postura foi motivo de discussão em um dos encontros de avaliação realizado pelo grupo.

Participante do grupo: "O que eu não achei muito interessante foi que você fez os alunos voltarem ao paralelogramo anterior, aquele que os ângulos eram internos. Você poderia ter os deixado terminar a conclusão que estavam chegando. A questão é que a partir do momento que você faz o aluno voltar, você acaba tirando um pouco da atenção dele e ele acaba perdendo aquele entusiasmo que ele estava com a atividade."

Professora da turma: "Na realidade aconteceu que eles fizeram isso, arrastaram os pontos e os ângulos ficarem externos. Então fui e expliquei. Só que falei para eles que "isso não é a questão da aula, é para a gente trabalhar os ângulos internos..." daí eu falei que o restante do ângulo externo seria a soma com o ângulo interno para dar 360 . Então expliquei para todos os grupos. Quando começaram a ficar alvoroçados falei que "o foco da aula não é esse, é para ver os ângulos internos" então eles falaram "ah não, ta bom, ta bom...". Eles até começaram a calcular os ângulos externos para achar os ângulos internos e tal. Mas depois eles voltaram para o foco da aula."

Nesse caso é possível notar que professora da turma recuou perante a zona de risco, conduzindo o grupo de volta ao que ela considerava como "foco da aula", parecendo negligenciar toda a proposta de atividades investigativas também estudadas pelo grupo. De acordo com Penteado (2001) isso é comum já que em alguns momentos prevalece a tendência de auto proteção do professor, mostrando a tensão que envolve o estar em uma zona de risco e ir para uma zona de conforto.

Outra atividade também levou a futura professora a se deparar em uma zona de risco. A atividade destacada na Figura 6 , os alunos investigavam a propriedade de que em duas retas concorrentes os ângulos opostos pelo vértice são sempre iguais. 


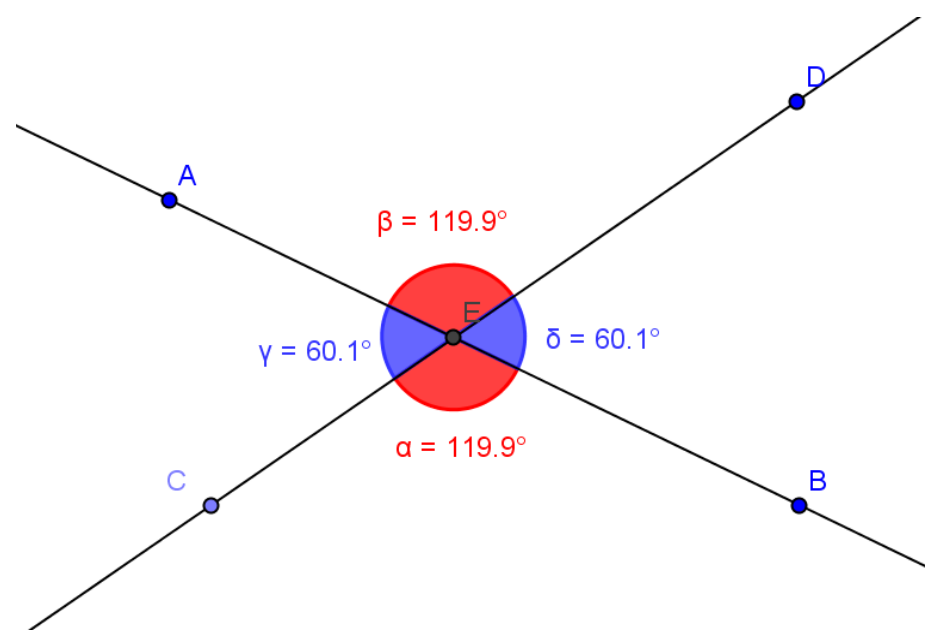

Figura 6-Atividade elaborada pelo grupo

Aparentemente também não havia nenhuma dificuldade em trabalhar com essa atividade. Apesar disso, um dos estudantes arrastou o ponto $C$ de forma que ele ficou entre os pontos $E$ e $D$ e o software mudou a marcação dos ângulos, dando a falsa sensação de que o teorema explorado pela atividade não era válido (Figura 7).

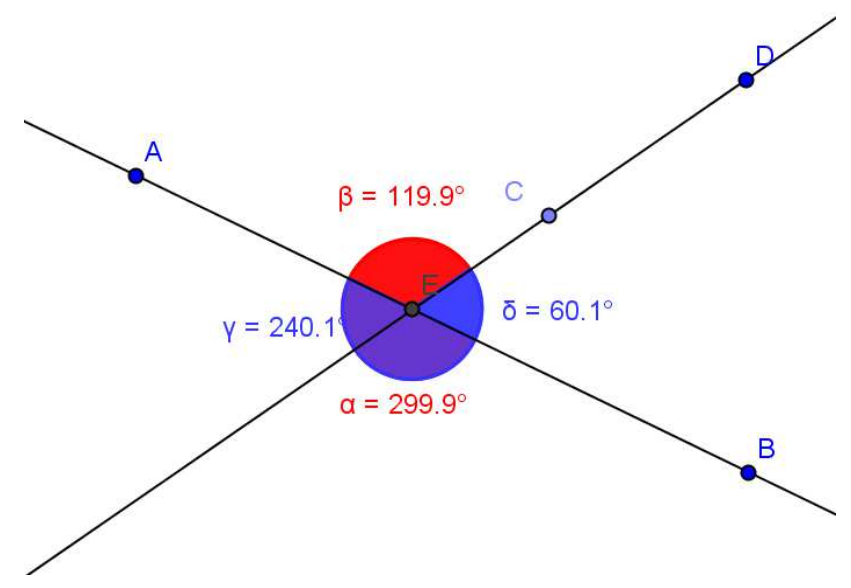

Figura 7-Atividade elaborada pelo grupo

Da mesma forma que a atividade do paralelogramo, a marcação dos ângulos acabou sendo uma limitação do Geogebra no trabalho com ângulos. Observando essa atividade passo a passo é possível entender como essa limitação ocorreu.

Depois de construído as retas concorrentes marcaram-se os pontos A e B sobre uma reta e os pontos $C$ e $D$ sobre a outra. $O$ ponto $E$ é a intersecção das duas retas. Marcou-se o ângulo $C E \hat{B}$ obtendo $119,99^{\circ}$ (Figura 8). 


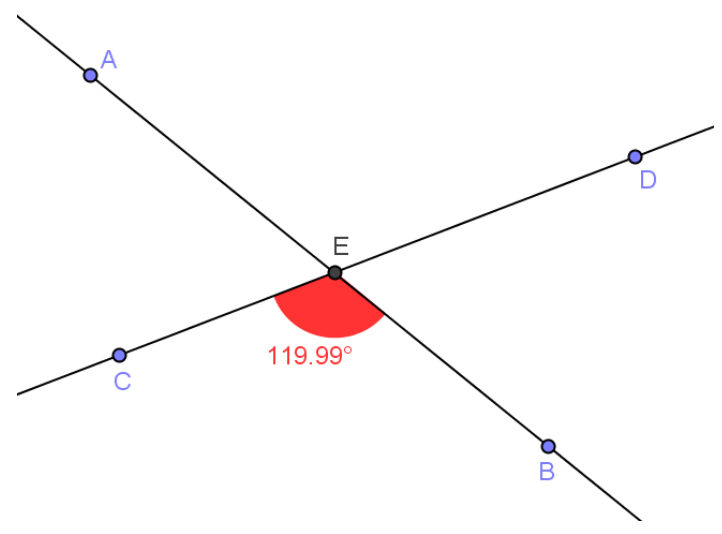

Figura 8-ângulo $C \hat{E} B$

Ao arrastar o ponto $C$ de forma que ele fique entre os pontos $E$ e $D$ a marcação do ângulo “muda" para 299,99\%, conforme mostra a Figura 9.

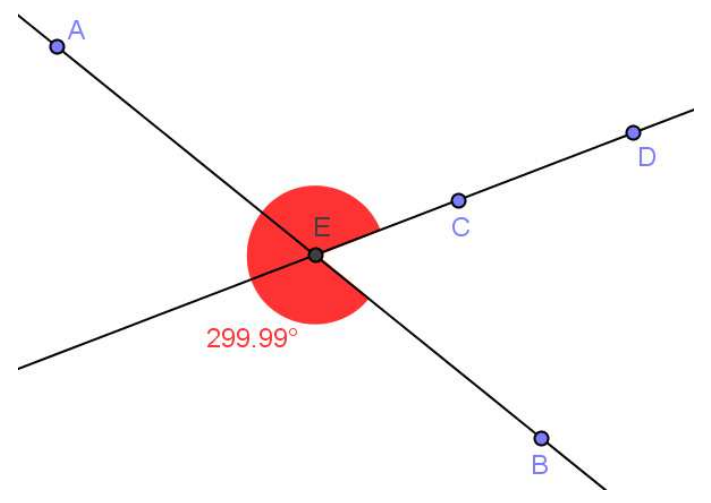

Figura 9

Isso ocorre já que o Geogebra trabalha com marcações de ângulos até $360^{\circ}$. Para ele o ângulo $C \hat{E} B$ é igual ao ângulo $D \hat{E} B$, e o programa entende que ambos são diferentes do ângulo $B \hat{E} D$. Quando o usuário marca o ângulo $D \hat{E} B$, seguindo o sentido horário, o Geogebra exibe o ângulo "externo", ou seja, obtuso (Figura 10). 


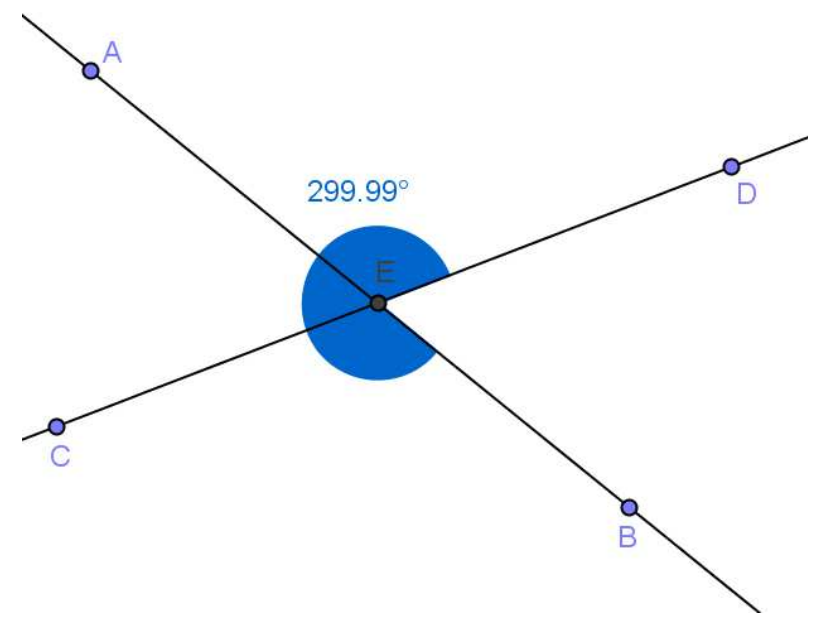

Figura 10

Quando o usuário marca o ângulo $B E \hat{E} D$, seguindo o sentido anti-horário, o programa exibe o ângulo "interno" (Figura 11). Dessa maneira o processo de marcação dos ângulos é diferenciado de um ponto para o outro. Por exemplo, para marcar o ângulo $D E \hat{E} B$ o usuário deve escolher a ferramenta "Ângulo" e clicar, nessa ordem, nos pontos $D, E$ e $B$. Diferentemente, a marcação do ângulo $B \hat{E} D$ é feita clicando, nessa ordem, nos pontos $B, E$ e $D$.

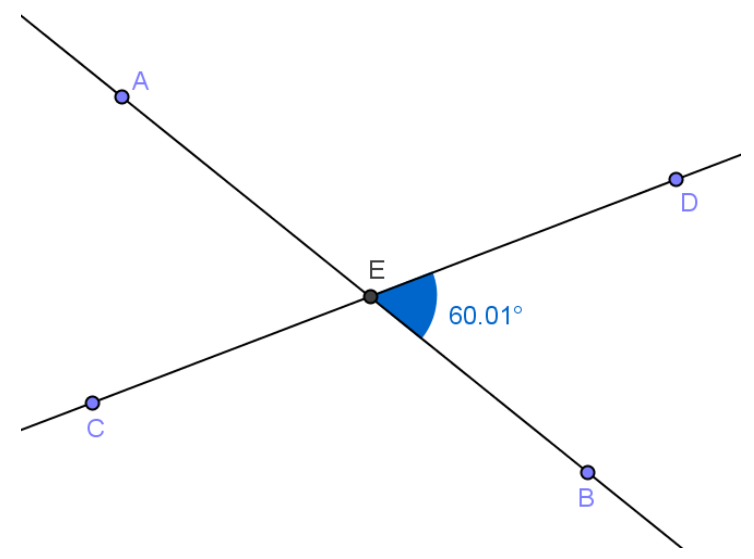

Figura 11 - Ângulo BÊD

De forma conceitual, não existe falha nessa perspectiva dos programadores do software. Apesar disso, ao elaborar a atividade dos ângulos opostos pelo vértice, os participantes do grupo de estudos desconheciam essa característica do Geogebra e, de certa forma, acabaram entrando em uma zona de risco.

Mesmo ocorrendo os imprevistos em um ambiente de aprendizagem baseado na utilização das TIC, Penteado e Skovsmose (2008) valorizam que caminhando em direção à zona de risco o 
professor pode aperfeiçoar sua prática profissional, pois a incerteza e a imprevisibilidade geradas nesse podem trazer possibilidades para o desenvolvimento do aluno, do professor e de situações de ensino e aprendizagem. Além disso, uma zona de risco possui a potencialidade de provocar mudanças e impulsionar o desenvolvimento de todos os envolvidos. Dessa forma o professor que utiliza as TIC em seu cotidiano deve conhecer as potencialidades e limitações de cada programa no sentido de tornarem-se possibilidades de aprendizagem.

Após o fato ocorrido durante a aplicação da atividade de ângulos opostos pelo vértice, o grupo de estudos se reuniu novamente e refletiram juntos até encontrarem uma solução para o problema apresentado na atividade. Concordando com Penteado e Skovsmose (2008) são atitudes como essas que fazem a zona de risco propiciar uma possibilidade para aprendizagem.

Outro fato a se destacar é a importância do professor conhecer diferentes softwares para tratar do mesmo tema. No caso dessa última atividade apresentada, o imprevisto não ocorreria se os futuros professores tivessem usado o Cabri-Géomètre. Dessa forma, a opção dos programadores do software acaba influenciando na maneira que cada usuário trabalha com o ambiente de geometria dinâmica. Nesse caso o imprevisto não ocorreria pois o Cabri-Géomètre trabalha com marcações de ângulos menores ou iguais a $180^{\circ}$. Isso pode ser notado na Figura 12 , onde foi elaborada a mesma atividade sobre ângulos opostos pelo vértice no Cabri.

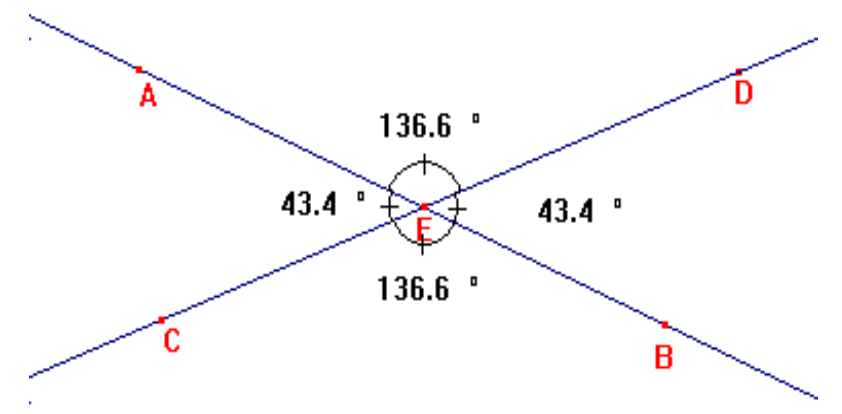

Figura 12 - Atividade de ângulos opostos elaborada no Cabri

Arrastando os pontos da mesma forma que na atividade elaborada no Geogebra a marcação do ângulo AÊC fica igual ao ângulo AÊD, conforme mostra a Figura 13. O mesmo ocorre com os ângulos $C \hat{E} B$ e $D E \hat{E} B$. Para o Cabri, não importa a ordem de marcação dos ângulos, ou seja, o ângulo DÊB é igual ao ângulo BÊD. 


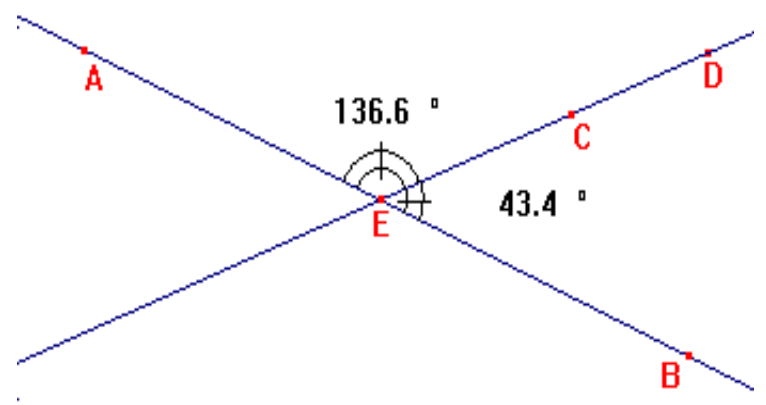

Figura 13 - Atividade elaborada no Cabri

\section{Considerações finais}

Destacou-se nesse artigo a importância do futuro professor conhecer e trabalhar em um ambiente de geometria dinâmica, já que apresentam grande potencial para explorar a matemática de uma forma interativa, convidando os estudantes a construir novos conhecimentos. Apesar disso, vimos que tais ambientes são mais propícios a ocorrer imprevistos do que ambientes que utilizam recursos tradicionais, caracterizando o que Penteado (2001) define como zona de risco. Defende-se que tais imprevistos devem ser explorados pelo professor pois é o movimento entre uma zona de conforto e uma zona de risco de trará maior possibilidade de aprendizagem dos alunos e também do professor.

Foram destacados episódios que ocorreram com futuros professores de matemática que trabalharam em um grupo de estudos, desenvolvendo uma oficina pedagógica com diversas atividades de geometria dinâmica para alunos do primeiro ano do ensino médio. Esse grupo foi importante para o sucesso da oficina já que propiciou autonomia e apoio mútuo entre os participantes, além de fornecer momentos de estudos teóricos que foram determinantes, principalmente quando fatos imprevistos surgiram ao desenvolver as atividades na escola pública. Isso vem ao encontro do que afirmam Borba e Penteado (2001), já que "é o pensar e agir coletivo que poderão impulsionar e manter o professor numa zona de risco de forma que ele possa usufruir o seu potencial de desenvolvimento" (p.68).

Outra consideração importante é que os ambientes de geometria dinâmica possuem uma maior facilidade para que atividades investigativas sejam elaboradas. $O$ arrastar permite que $o$ estudante crie e explore suas próprias conjeturas. Apesar disso, é muito importante que as atividades elaboradas nesse ambiente sejam bem direcionadas. No caso do grupo de estudos da presente pesquisa, a abordagem da oficina realizada foi baseada em Skovsmose (2008) e Ponte, Brocardo e Oliveira (2006), onde os autores, mesmo não necessariamente utilizando um 
ambiente computacional, apresentam diversos recursos para que o professor crie um ambiente de aprendizagem que facilite a investigação. Concordando com Valente (1993) os ambientes de geometria dinâmica não podem ser uma extensão do que já ocorre tradicionalmente na sala de aula.

Para encerrar, destaca-se a necessidade do professor conhecer as limitações do software que utiliza em suas aulas, pois a maneira de pensar dos programadores acaba influenciando a maneira de lidar com o programa. $O$ artigo evidenciou passo a passo como o Geogebra trata a marcação dos ângulos, enfatizando assim a necessidade de adaptar as atividades, diminuindo a margem para outras interpretações nas mesmas. O fato é que as TIC estão presentes em todos os ramos e na educação apresentam uma infinidade de recursos. Utilizar um ambiente de geometria dinâmica de uma forma investigativa é apenas uma, das várias abordagens que as TIC propiciam para professores. A iniciativa da formação do grupo de estudos com licenciandos em matemática pode ser uma iniciativa também adotada nas escolas com professores em serviço, visto que as discussões e avaliações realizadas pelos participantes do grupo de estudos foram fundamentais para o sucesso das oficinas na escola pública.

\section{Referências}

Baulac, Y., Bellemain, F., Laborde, J.M. (designers); CABRI II [Computer software]. Dallas, TX, Texas Instruments, 1994.

Bicudo, M.A.V., Pesquisa qualitativa e pesquisa qualitativa segundo a abordagem fenomenológica. In: Borba M.C. e Araújo J.L. Pesquisa qualitativa em educação matemática, Belo Horizonte: Autêntica, 2006. p.101 a 114.

Borba, M.C.; Penteado, M.G. Informática e educação matemática - 2.Ed. Belo Horizonte Autêntica, 2001.

Clements D.H., Sarama, J., Yelland N.J., Glass, B. Learning and teaching geometry with computers in the elementary and middle school. In: Blume G.W., Heid, M.K., (Eds). Research on technology and the teaching and learning of Matematics: Vol 1. Research Systheses. Charlotte, North Carolina, USA: Information Age Publishing, Inc., 2008, p.109-154.

Goldenberg, E.P., Scher, D., Feurzeig, N. What lies behind dynamic interactive geometry software? In: Blume G.W., Heid, M.K., (Eds). Research on technology and the teaching and learning of 
Matematics: Vol 2. Cases and Perspectives. Charlotte, North Carolina, USA: Information Age Publishing, Inc., 2008, p.53-88.

Golderberg, E.P.; Cuocco, A.A.; What is dynamic geometry? In: LEHER, R., CHAZAN, D. (Eds); Designing learning environments for developing urderstanding of geometry and space.London: Lawrence Erlbaum Associates, 1998, p. 350 - 367.

Hohenwarter, M. (designer); Geogebra - Dynamic Mathematics for Schools, versão 3.0, [computer software] 2007; Departamento de Matemática Aplicada da Universidade de Salzburgo, Áustria.

Hollebrands, K., Laborde, C., Sträber, R. Technology and the learning of geometry at the secondary level. In: Blume G.W., Heid, M.K., (Eds). Research on technology and the teaching and learning of Matematics: Vol 1. Research Systheses. Charlotte, North Carolina, USA: Information Age Publishing, Inc., 2008, p.155-206.

Jackin, N. (Designer). The Geometer's Sketchpad, v4.0 [computer software].Barkeley, CA: Key Curriculum Press, 2001.

Laborde, C., Laborde J. The development of a dynamical geometry environment: Cabri-Géomètre. In: Blume G.W., Heid, M.K., (Eds). Research on technology and the teaching and learning of Matematics: Vol 2. Cases and Perspectives. Charlotte, North Carolina, USA: Information Age Publishing, Inc., 2008, p.31-52.

Olive J.; Opportunities to explore and integrate mathematics with the Geometer's Sketchpad. In: Leher, R., Chazan, D. (Eds); Designing learning environments for developing urderstanding of geometry and space.London: Lawrence Erlbaum Associates, 1998 (p.395-418).

Penteado, M.G. Computer-based learning environments: risks and uncertainties for teacher. Ways of knowing Journal, 1 (2), 23-35, 2001.

Penteado, M.G., Skovsmose, O.; Riscos trazem possibilidades. In: Skovsmose, O. Desafios da reflexão em educação matemática crítica. Coleção Perspectivas em Educação Matemática; tradução: Orlando de Andrade Figueiredo, Jonei Cerqueira Barbosa. - Campinas - SP: Papirus, 2008, (p.41-51).

Ponte, J.P.; Brocardo, J.; Oliveira, H. Investigações Matemáticas na sala de aula. (Coleção Tendências em Educação Matemática, 7). Belo Horizonte: Autêntica, 2006, 152 p.

Richit, A.; Projetos em geometria analítica usando software de geometria dinâmica: Repensando a formação inicial docente em Matemática. 2005. Dissertação (Mestrado em Educação Matemática) - Instituto de Geociências e Ciências Exatas, Universidade Estadual Paulista, Rio Claro.

Silva, G.H.G.; Grupos de estudo como possibilidade de formação de professores de matemática no contexto da geometria dinâmica, 2010. Dissertação (Mestrado em Matemática) - Instituto de Geociências e Ciências Exatas, Universidade Estadual Paulista, Rio Claro.

R. B. E. C. T., vol 5, núm 1, jan./abr. $2012 \quad$ ISSN - 1982-873X 
Skovsmose, O. Desafios da reflexão em educação matemática crítica. Coleção Perspectivas em Educação Matemática; tradução: Orlando de Andrade Figueiredo, Jonei Cerqueira Barbosa. Campinas - SP: Papirus, 2008, 138 p.

Valente, J.A. Computadores e conhecimento: repensando a educação. Campinas, SP: UNICAMP, 1993.

Valente, J.A.; Formação de educadores para o uso da informática na escola. Campinas, SP:

UNICAMP/NIED, 2003.

Guilherme Henrique Gomes da Silva. Universidade Federal de Alfenas. Professor na Universidade Federal de Alfenas, campus de Varginha, no Instituto de Ciências Sociais Aplicadas, lecionando disciplinas na área de Matemática. Mestre em Educação Matemática pela Universidade Estadual Paulista Júlio de Mesquita Filho. guilhermehgsilva@gmail.com 